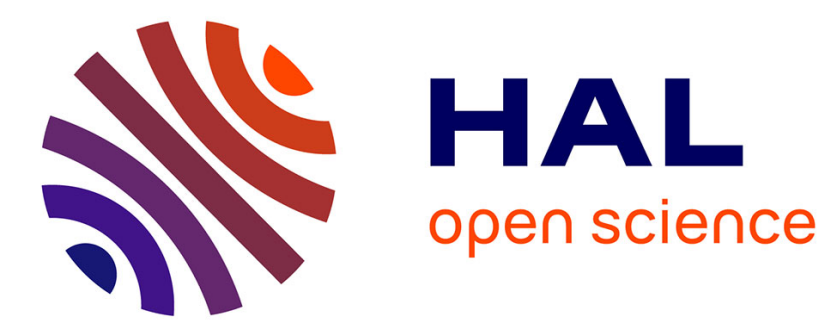

\title{
Electrochemical Oxidation of Carbon Monoxide on Unsupported Gold Nanospheres in Alkaline Medium
}

Nolwenn Mayet, Karine Servat, K. Boniface Boniface Kokoh, Teko Napporn

\section{To cite this version:}

Nolwenn Mayet, Karine Servat, K. Boniface Boniface Kokoh, Teko Napporn. Electrochemical Oxidation of Carbon Monoxide on Unsupported Gold Nanospheres in Alkaline Medium. Electrocatalysis, 2020, 10.1007/s12678-020-00626-7 . hal-03049296

\section{HAL Id: hal-03049296 https://hal.science/hal-03049296}

Submitted on 9 Dec 2020

HAL is a multi-disciplinary open access archive for the deposit and dissemination of scientific research documents, whether they are published or not. The documents may come from teaching and research institutions in France or abroad, or from public or private research centers.
L'archive ouverte pluridisciplinaire HAL, est destinée au dépôt et à la diffusion de documents scientifiques de niveau recherche, publiés ou non, émanant des établissements d'enseignement et de recherche français ou étrangers, des laboratoires publics ou privés. 


\section{Electrochemical oxidation of carbon monoxide on unsupported gold nanospheres in alkaline medium}

Nolwenn Mayet, Karine Servat, K. Boniface Kokoh *, and Teko W. Napporn *

Université de Poitiers, IC2MP, UMR-CNRS 7285, 4 rue Michel Brunet, B27, TSA 51106, 86073 Poitiers Cedex 09, France

${ }^{*}$ Corresponding authors:

E-mail address: boniface.kokoh@univ-poitiers.fr (K.B. Kokoh).

ORCID: 0000-0002-5379-7792

E-mail address: teko.napporn@univ-poitiers.fr (T.W. Napporn)

ORCID: 0000-0003-1506-7139 


\begin{abstract}
Carbon monoxide (CO) is intensively studied as a model molecule for organics oxidation reaction or as a strong adsorbate on noble metal surfaces. In this work, quasi-spherical gold nanoparticles (AuNPs) prepared by a revisited Turkevich method were electrochemically characterized. Physical and electrochemical measurements demonstrated the presence of (111) and (110) facets. These unsupported NPs were used to study the effect of the upper potential limit and gold oxide formation on $\mathrm{CO}$ oxidation in alkaline medium. The results demonstrate that hydroxide species are crucial to oxidize $\mathrm{CO}$, whereas the gold oxides species do not play a critical role.
\end{abstract}

Key words: carbon monoxide, electrocatalysis, gold nanoparticles, cyclic voltammetry, underpotential deposition 


\section{Introduction}

The electrochemical oxidation of organic molecules leads often to the formation of carbon monoxide which is considered as a poisoning specie for various noble metal electrodes like platinum [1]. Therefore, the oxidation of carbon monoxide (CO) becomes one of the most investigated reaction in electrocatalysis in the aim of finding the efficient way for overcoming the electrode deactivation due to its strong adsorption. On Pt electrode, $\mathrm{CO}$ electro-oxidation is extensively studied both in acid and alkaline media for understanding the reaction mechanism and to fabricate tolerant and active electrode materials [2]. For this purpose, the use of disseminated noble metal nanoparticles on high specific surface area materials as the carbon substrate is a way to avoid strong adsorption of $\mathrm{CO}$ and promote its oxidation. Conversely to platinum which strongly interacts with $\mathrm{CO}$, bulk gold is considered as the most stable and less active metal [3]. Therefore, under standard conditions, the poisoning effect by CO usually evidenced electrochemically on Pt by CO stripping is not commonly experienced on Au. Indeed, the electrochemical interaction between the surface of bulk gold electrode and CO was earlier studied in 1960s' by Roberts et al. [4] in acid and alkaline media. The important role of hydroxides in the oxidation process was pointed out. In heterogeneous catalysis, the oxidation of CO is widely studied on supported gold nanoparticles. Indeed, a pioneer work by Haruta et al. $[5,6]$ showed that gold nanoparticles (AuNPs) deposited on transition metal oxides (Fe, Co, $\mathrm{Ni}, \mathrm{Ti}$ ) can oxidize $\mathrm{CO}$ at a temperature as low as $-70^{\circ} \mathrm{C}$. These investigations have confirmed the outstanding properties of gold at nanoscale in heterogeneous catalysis. Carbon monoxide oxidation on the bulk gold surface was studied electrochemically [7-13]. Particularly, the studies of $\mathrm{CO}$ electrochemical oxidation reaction in alkaline and acid media were reported on different low-index gold single-crystals surfaces and on supported gold nanoparticles $[7,8,10$, 14-17]. This reaction strongly depends on the electrolyte $\mathrm{pH}$ and the structure of the surface [10]. Contrary to platinum or palladium, the molecule of CO weakly interacts with the gold surface [18]. It was shown that CO is irreversibly adsorbed on the (111) plane [15]. The studies concerning the $\mathrm{CO}$ oxidation on gold AuNPs reported mostly the effect of the presence of a metallic oxide support such as $\mathrm{TiO}_{2}, \mathrm{Fe}_{2} \mathrm{O}_{3}$ or $\mathrm{Co}_{3} \mathrm{O}_{4}[11,16,19]$. Moreover, gold nanoparticles are considered as inactive in gas phase towards this reaction when they are unsupported and when the size is higher than $10 \mathrm{~nm}$ [11]. Studies in gas phase demonstrated the interaction between hydroxyl species and carbon monoxide towards water gas shift reaction [20]. In electrocatalysis, investigations on unsupported nanoparticles appear as one of the suitable approaches to understand their intrinsic properties towards a reaction. To our knowledge, only 
two works concern the behavior of unsupported AuNPs towards CO electrochemical oxidation, particularly the effect of the particle coverage of an ITO electrode and the size of the NPs [21, 22]. It is also reported that a synergetic effect was observed for this reaction by combining gold with others metals like $\mathrm{Ag}$ ( $\mathrm{Au}-\mathrm{Ag})$ or Pd (Au-Pd) [23-25].

In alkaline medium, the presence of $\mathrm{CO}$ promotes the adsorption of hydroxide ions $\left(\mathrm{HO}^{-}\right)$on the gold surface $[7,10,26]$. Indeed, the weakly adsorbed $\mathrm{CO}$ leads to a shift of the $\mathrm{HO}^{-}$ adsorption toward lower potentials. At higher potentials, $\mathrm{CO}$ molecules react with co-adsorbed $\mathrm{HO}^{-}$species to form carbohydroxyl species.

In this work, the electrochemical interaction between $\mathrm{CO}$ and unsupported spherical gold nanoparticles synthesized by citrate reduction method was investigated in alkaline medium using a rotating disk electrode. Contrary to the already reported works on CO oxidation at gold nanoparticles, the present investigation concerns unsupported gold nanoparticles deposited on a rotating glassy carbon disk electrode. Extensively, the surface of AuNPs was electrochemically evaluated by lead underpotential deposition ( $\mathrm{Pb}$ upd $)$ as well as the effect of upper limit potential on the oxidation of $\mathrm{CO}$.

\section{Experimental}

\subsection{Synthesis}

The AuNPs were synthesized from the method developed by Turkevich [27-29]. A solution $(19 \mathrm{~mL})$ containing $5 \times 10^{-6} \mathrm{~mol}$ of $\mathrm{HAuCl}_{4}$ was heated in a flask with an oil bath until $80{ }^{\circ} \mathrm{C}$ with vigorous stirring. Then, $1 \mathrm{~mL}$ of a $0.5 \%$ trisodium citrate solution was added to the flask. The solution was kept stirred at $80{ }^{\circ} \mathrm{C}$ for 30 minutes. Finally, the colloidal solution was cooled down at ambient temperature $\left(20{ }^{\circ} \mathrm{C}\right)$ before its centrifugation. $2 \mathrm{~mL}$ of this solution was centrifuged at $10000 \mathrm{rpm}$ during $10 \mathrm{~min}$. The bottom fraction was washed with ultrapure water and centrifuged at $8000 \mathrm{rpm}$. The final bottom fraction was used directly as the catalytic ink. Therefore, $5 \mu \mathrm{L}$ of this fraction was dropped on the glassy carbon disk. This volume represents $30 \mu \mathrm{g} \mathrm{cm}^{-2}$ of gold, which covers the surface. After drying with nitrogen, the as-prepared AuNPs electrode is ready for electrochemical characterization.

\subsection{Physical Characterizations}

Transmission electron microscopy (TEM and HR-TEM for high resolution) analysis was performed in a JEOL 2100 UHR microscope operating at an acceleration voltage of $200 \mathrm{kV}$. 
UV-vis spectra was recorded with a spectrophotometer Helios Omega UV-vis/NIR (Thermo Fisher) with quartz cell (optical path $=1 \mathrm{~cm}$ ). The crystalline structure of samples was studied by X-ray diffraction (XRD) on a PANAnalytical "Empyrean" diffractometer in the $2 \theta$ range $20-120^{\circ}$ using Co K $\alpha$ X-ray irradiation source $(\lambda=0.1789 \mathrm{~nm})$. The colloidal solution of AuNPs was dropped on a single crystal Si (which has a very low background) and dried under nitrogen flow. Indexation of the different phases was determined using HighScore software.

\subsection{Electrochemical characterizations}

The glassware was cleaned with an acidic potassium permanganate solution and then an acidic hydrogen peroxide solution. Afterwards, the glassware was rinsed with hot water and finally rinsed with ultrapure water $\left(18.2 \mathrm{M} \Omega \mathrm{cm}\right.$ at $\left.20^{\circ} \mathrm{C}\right)$. A three-electrode Pyrex glass cell was employed with a reversible mercury oxide reference electrode then converted as hydrogen reference electrode (the potential was converted as $0.926 \mathrm{~V}$ vs. RHE); a glassy carbon slab electrically connected with a gold wire served as counter electrode, while a glassy carbon disk (GC) of $0.07 \mathrm{~cm}^{2}$ was used as electrode support of the working catalysts. Before each experiment, the GC electrode was polished with alumina $0.5 \mu \mathrm{m}$ and cleaned in ultrapure water under sonication. A voltammogram of the GC electrode was recorded to verify its cleanliness. The supporting electrolyte was a $0.1 \mathrm{~mol} \mathrm{~L}^{-1} \mathrm{NaOH}$ solution, deaerated by bubbling nitrogen to remove any dissolved oxygen before each experiment. A nitrogen stream was maintained over the electrolytic solution during the measurement in order to obtain an electrolyte free from oxygen. The electrochemically active surface area (EASA) of each AuNPs thin layer was estimated from electric charge of the reduction of Au oxides monolayer $\left(482 \mu \mathrm{C} \mathrm{cm}^{-2}\right)[30,31]$ in cyclic voltammetry at $50 \mathrm{mV} \mathrm{s}^{-1}$ and in $0.1 \mathrm{~mol} \mathrm{~L}^{-1} \mathrm{NaOH}$ from $0.05 \mathrm{~V}$ to $1.6 \mathrm{~V}$ vs. RHE. Underpotential deposition of lead (upd of lead) was carried out in $0.1 \mathrm{~mol} \mathrm{~L}^{-1} \mathrm{NaOH}+1 \mathrm{mmol}$ $\mathrm{L}^{-1} \mathrm{~Pb}\left(\mathrm{NO}_{3}\right)_{2}$ from $0.85 \mathrm{~V}$ to $0.25 \mathrm{~V}$ vs. RHE [32]. The growth of thick oxide layer were carried in $0.1 \mathrm{~mol} \mathrm{~L}^{-1} \mathrm{NaOH}$. First, linear polarizations were recorded from $0.05 \mathrm{~V}$ to $\mathrm{E}_{\text {sup }}\left(\mathrm{E}_{\text {sup }}=1.1\right.$ $\mathrm{V}, 1.2 \mathrm{~V}, 1.3 \mathrm{~V}, 1.4 \mathrm{~V}, 1,5 \mathrm{~V}$ and $1.6 \mathrm{~V} v s$. RHE) at $50 \mathrm{mV} \mathrm{s}^{-1}$. Carbon monoxide oxidation was carried out after bubbling CO during 20 minutes to saturate the electrolyte, and at different electrode rotation speeds (400, 900, 1600 and $2500 \mathrm{rpm})$ and different scan rates (10, 20 and $50 \mathrm{mV} \mathrm{s}^{-1}$ ). Then, chronoamperometry measurements were performed at $\mathrm{E}_{\text {sup }}$ during 7200 seconds. Electrochemical experiments were carried out with a potentiostat (PGSTAT-302) interfaced with Nova 1.8 software. 


\section{Results and discussion}

\subsection{Physical characterizations}

\subsubsection{Transmission electron microscopy}

The pictures from the Transmission Electron Microscopy (TEM) characterizations of the synthesized AuNPs were shown in Figure 1. The as-prepared AuNPs have a quasi-spherical shape and display twinned structures as shown in Figure $1 \mathrm{~b}$.

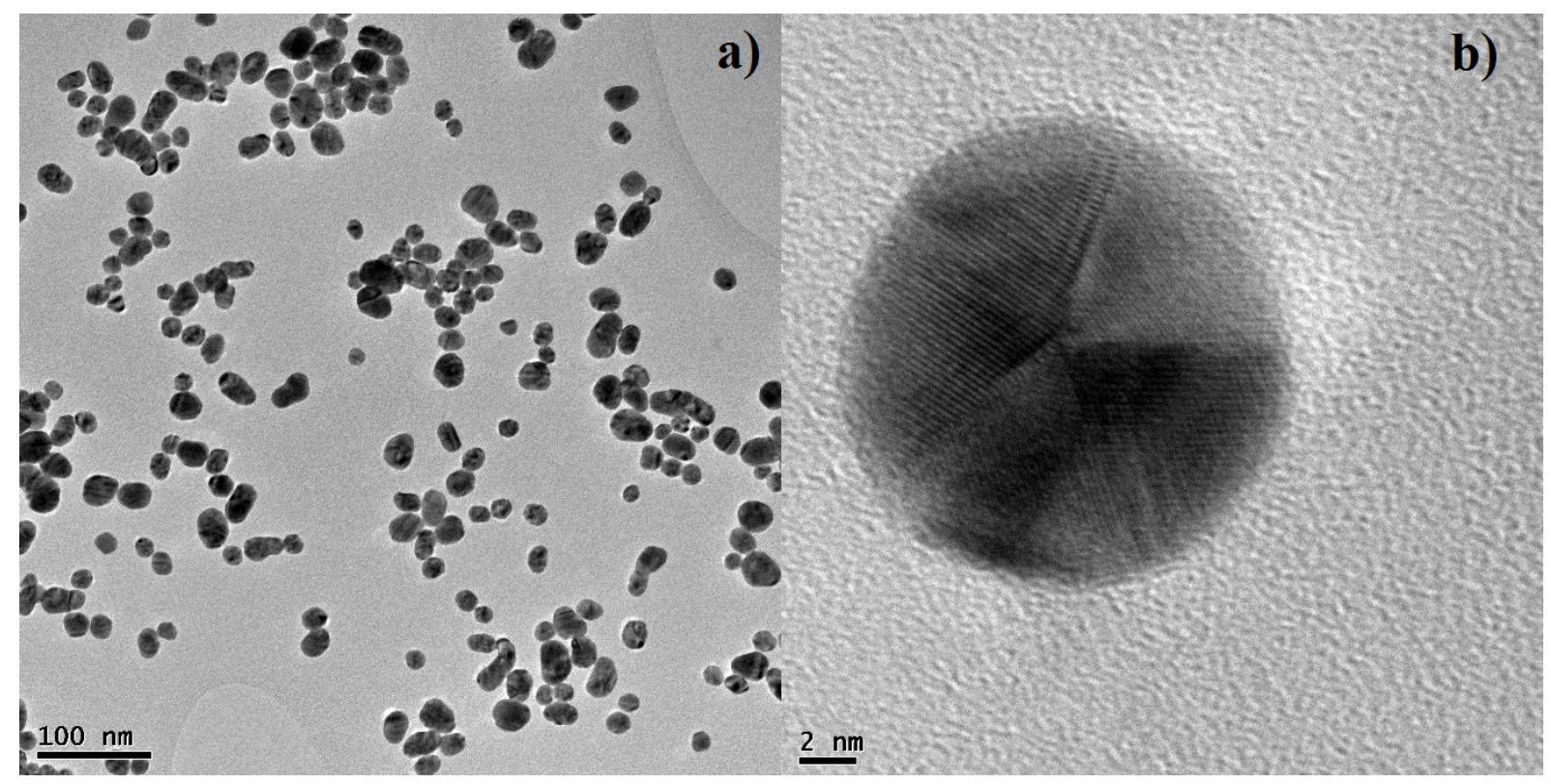

Figure 1: a) TEM image of the gold nanoparticles, b) HR-TEM of an isolated nanoparticle.

From the TEM image (Figure 1a), about 300 isolated AuNPs were counted to estimate the size distribution (Figure 2) which is in the range from 5 to $35 \mathrm{~nm}$; their mean size is evaluated to $23.04 \pm 3.37 \mathrm{~nm}$. First papers on this preparation method have reported size distributions of 1000 nanoparticles that varied between $14.50 \pm 1.30 \mathrm{~nm}$ and $24.00 \pm 2.90 \mathrm{~nm}$ according to the reaction parameters [27]. These values are close to the mean size obtained in this work. 


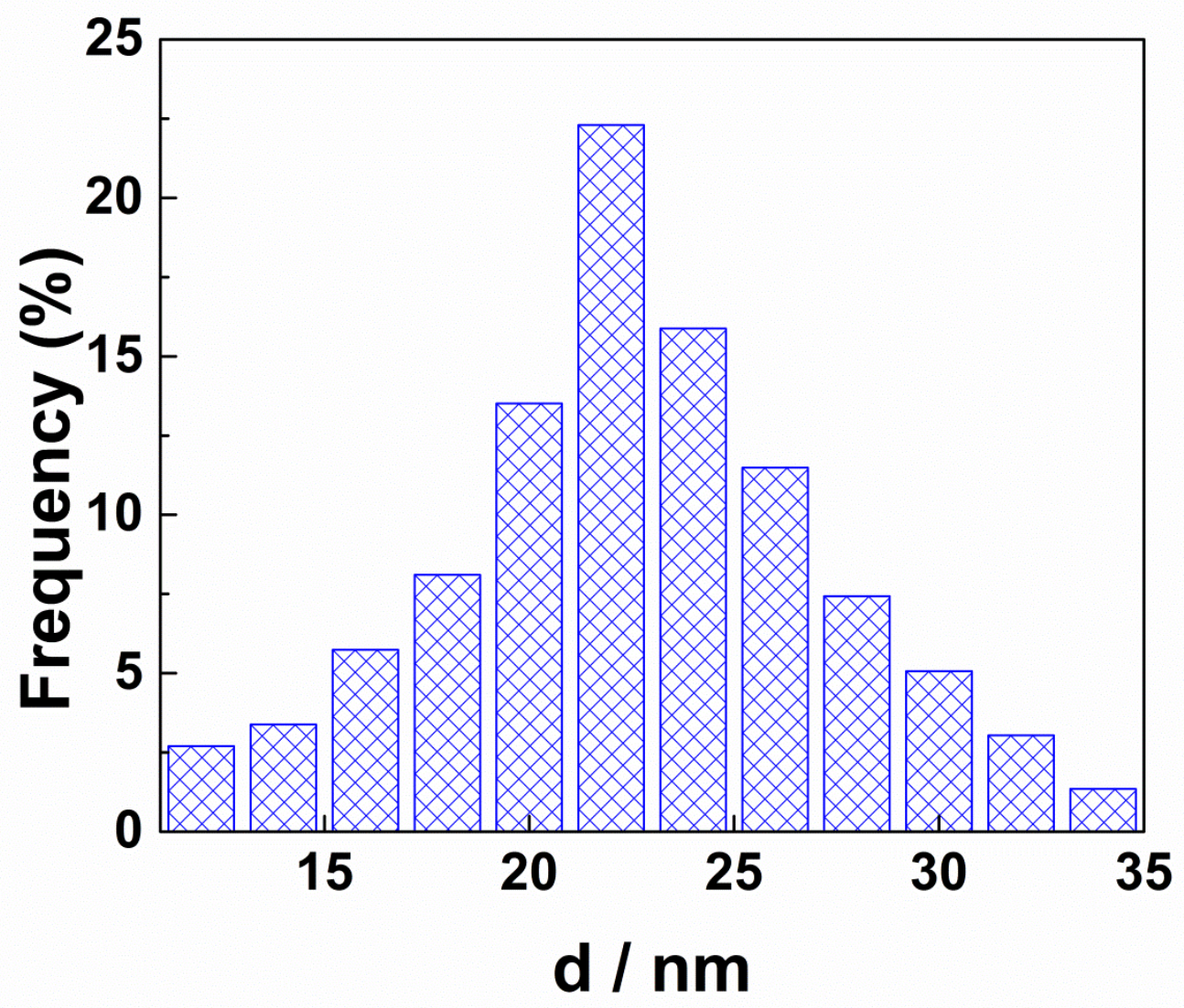

Figure 2: Distribution of the nanoparticles diameters (for about 300 nanoparticles).

\subsubsection{UV-visible measurement}

Figure 3 shows the UV-visible spectrum of the colloidal solution containing AuNPs. The spectrum displays a single plasmon peak centered at $520 \mathrm{~nm}$. When the size of nanoparticles increases, the peak associated with surface plasmon resonance (SPR) is shifted towards higher wavelengths (red shift) [33]. This single peak shape is typically observed for spherical gold nanoparticles $[34,35]$. The position of the peak corresponds to a nanoparticles size of about $20 \mathrm{~nm}$, which is confirmed by electron microscopy [36]. The width of the peak indicates the dispersion of the nanoparticles in the colloidal solution. Narrower the width of the SPR peak is, narrower is the size distribution [37]. In the present case, the width of the SPR peak is in agreement with the size distribution on Figure 2. 


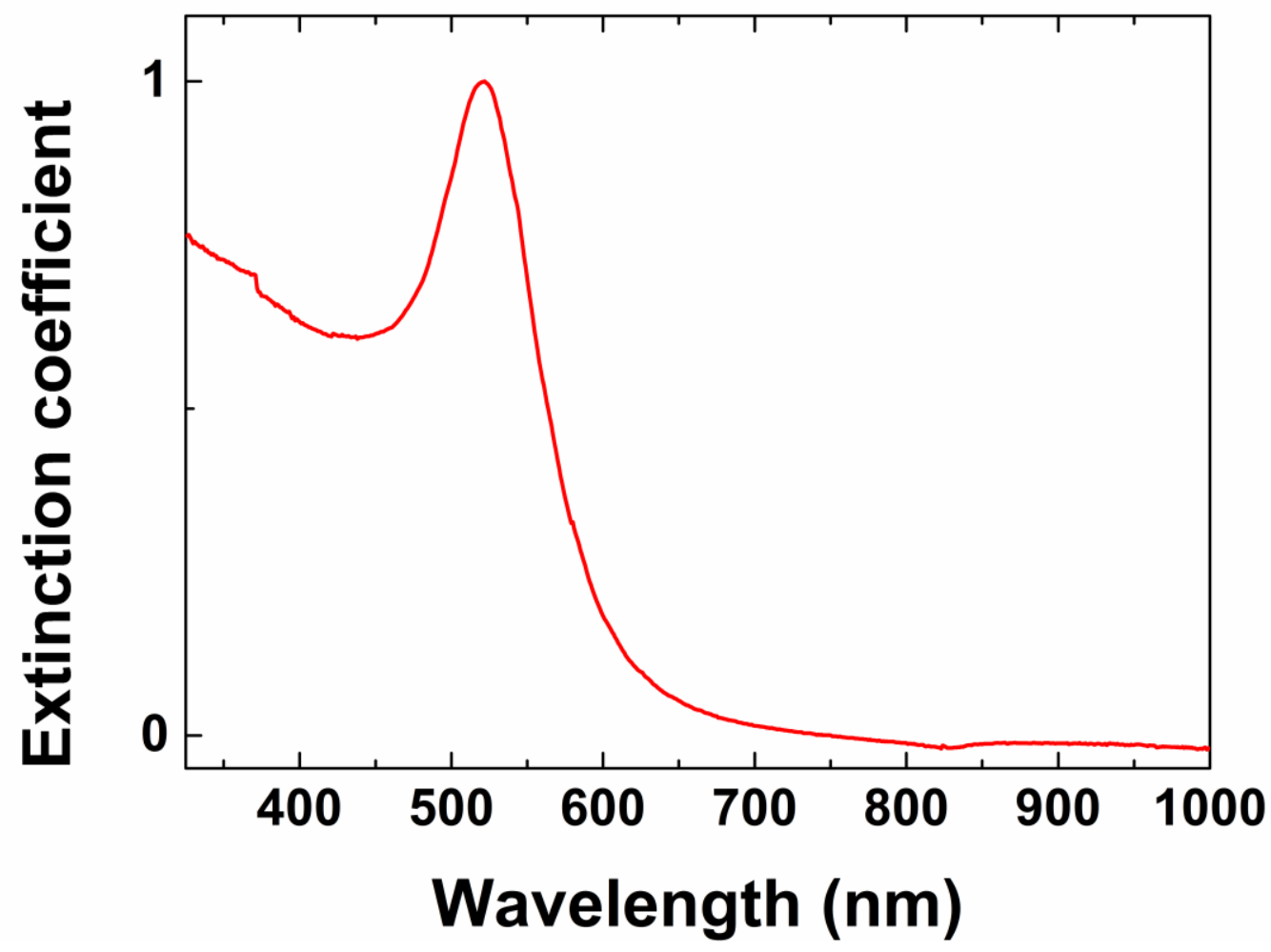

Figure 3: UV-visible spectrum of the colloidal solution containing gold nanoparticles.

\subsection{3. $X$-ray diffraction}

Figure 4 shows the diffractogram of the AuNPs. AuNPs are crystallized as face-centered cubic ( $f c c$ ) gold (JCPDS, file number 04-0784). The ratio of the intensity between (200) and (111) peaks is 0.20 . By comparison, the value for bulk polycrystalline gold is 0.53 [38]. This lower value suggests that the (111) plane was the predominant orientation of these prepared AuNPs with revisited Turkevich method. The ratio between the intensities of (220) and (111) planes is 0.08 , which is much lower than the value of 0.32 obtained on polycrystalline gold [39]. These values suggest that AuNPs are composed mostly of (111) planes with a low presence of (100) and (110) ones. 


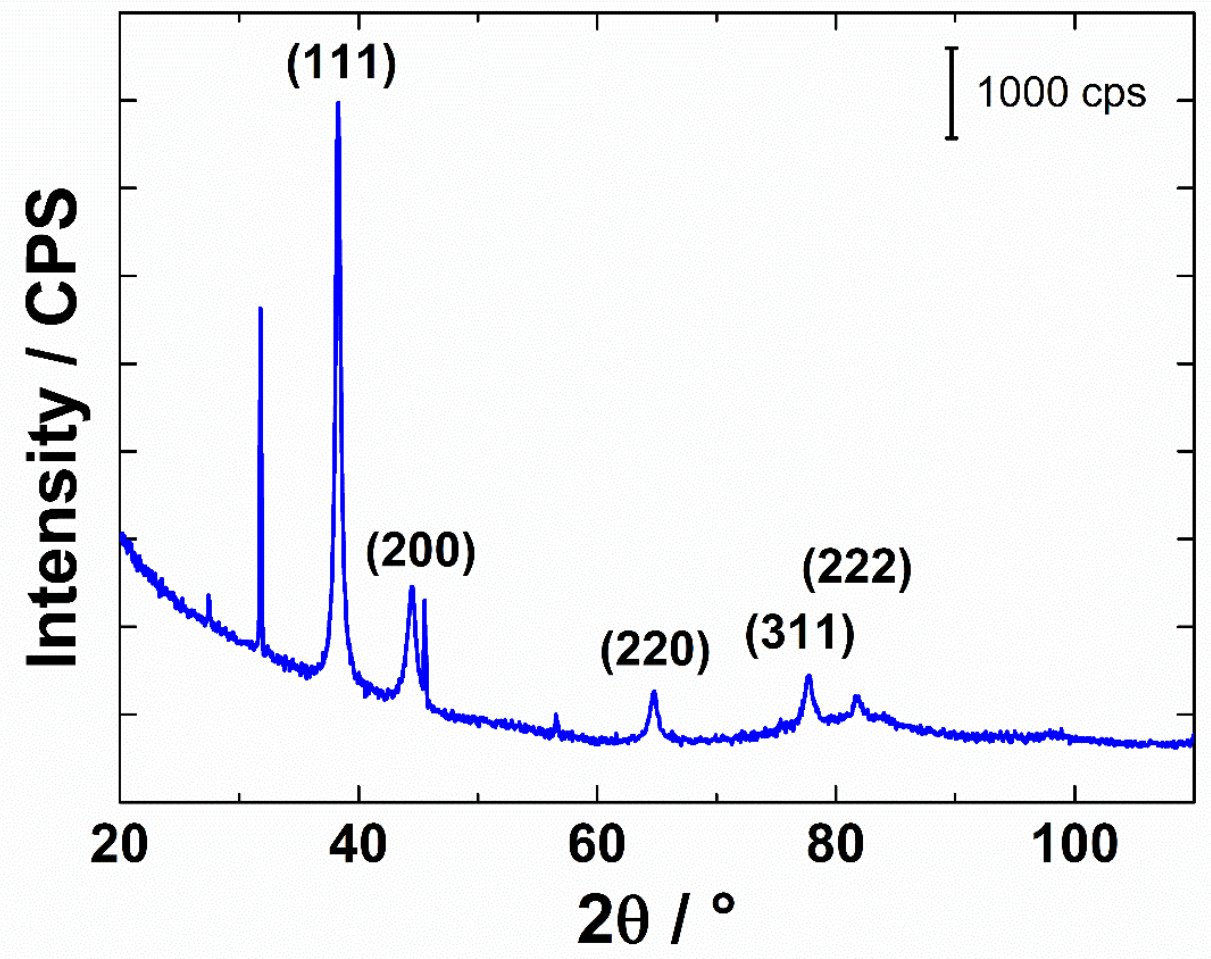

Figure 4: XRD patterns of AuNPs prepared from the revisited Turkevich method 


\subsection{Electrochemical characterizations}

\subsubsection{Effect of the upper potential limit}

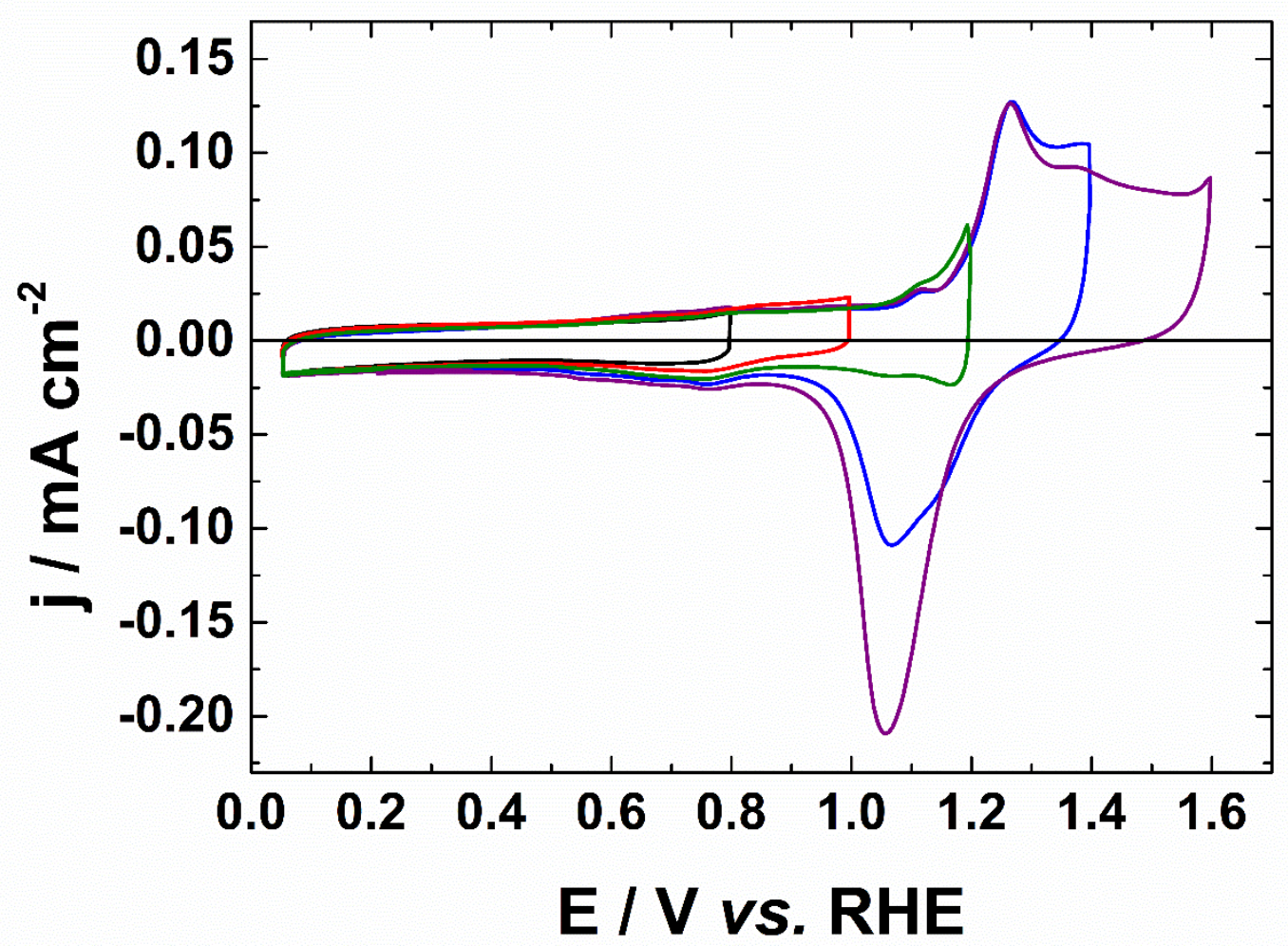

Figure 5: Cyclic voltammograms of AuNPs in $0.1 \mathrm{~mol} \mathrm{~L}^{-1} \mathrm{NaOH}$ recorded at $50 \mathrm{mV} \mathrm{s}^{-1}$ and at a temperature of $20^{\circ} \mathrm{C}$, for different upper potential limits $(0.8 \mathrm{~V}, 1.0 \mathrm{~V}, 1.2 \mathrm{~V}, 1.4 \mathrm{~V}$ and $1.6 \mathrm{~V} v s . \mathrm{RHE})$.

Figure 5 presents the CVs of AuNPs in alkaline medium recorded at $50 \mathrm{mV} \mathrm{s}^{-1}$. The CVs were performed at various upper potential limits $\left(\mathrm{E}_{\text {sup }}=0.8 \mathrm{~V}, 1.0 \mathrm{~V}, 1.2 \mathrm{~V}, 1.4 \mathrm{~V}\right.$ and $1.6 \mathrm{~V} v s$. RHE) to probe the oxidation states of the Au particles surface as function of the electrode potential. The $\mathrm{CV}$ recorded with $\mathrm{E}_{\text {sup }}=1.6 \mathrm{~V} v s$. RHE shows the fingerprint of gold with the double-layer region from $0.05 \mathrm{~V}$ to $0.9 \mathrm{~V} v s$. RHE, the oxidation surface from $1.1 \mathrm{~V} v s$. RHE and its reduction at a single peak at $1.05 \mathrm{~V} v s$. RHE. When the upper potential limit increases, the charge corresponding to the formation of the oxide increases. This is followed by the increase of the oxide reduction peak during the negative going scan. During the positive scan and until $0.8 \mathrm{~V}$ vs. RHE, the surface is not oxidized, and no reconstruction occurs, as mentioned in the literature [40, 41]. The adsorption of hydroxide species occurs from $0.3 \mathrm{~V}$ to $1.1 \mathrm{~V} v s$. RHE and involves a partial electron transfer [42]. The oxide formation/reduction is a complex and irreversible process. The origin of this irreversibility is attributed to the nature of the oxide film. 
Indeed, during the oxide growth process it is assumed that dipolar species as $\mathrm{Au}^{\delta+}-\mathrm{HO}^{\delta-}$ are formed, which repel each other, creating a place-exchange reaction [43]. The repulsion raises the energy required to create new dipoles. Hence, an increase in potential leads to an increase of the coverage. This effect explains the fact that the oxide region is a wide plate rather than a sharp peak. However, since the different crystallographic planes have different surface energies, the oxide region strongly depends on it, as the fingerprint of each single crystal is different [40, 41]. No electrostatic repulsion occurs during the negative potential sweep, a single sharp reduction peak is observed. The fingerprint of the oxide region is similar to polycrystalline gold. The oxidation peak at $1.25 \mathrm{~V} v s$. RHE is observed on (111) facets and the small peak at around $1.40 \mathrm{~V} v$ s. RHE is attributed to (100) facets [44].

\subsubsection{Underpotential deposition (upd) of lead on the as-synthesized AuNPs}

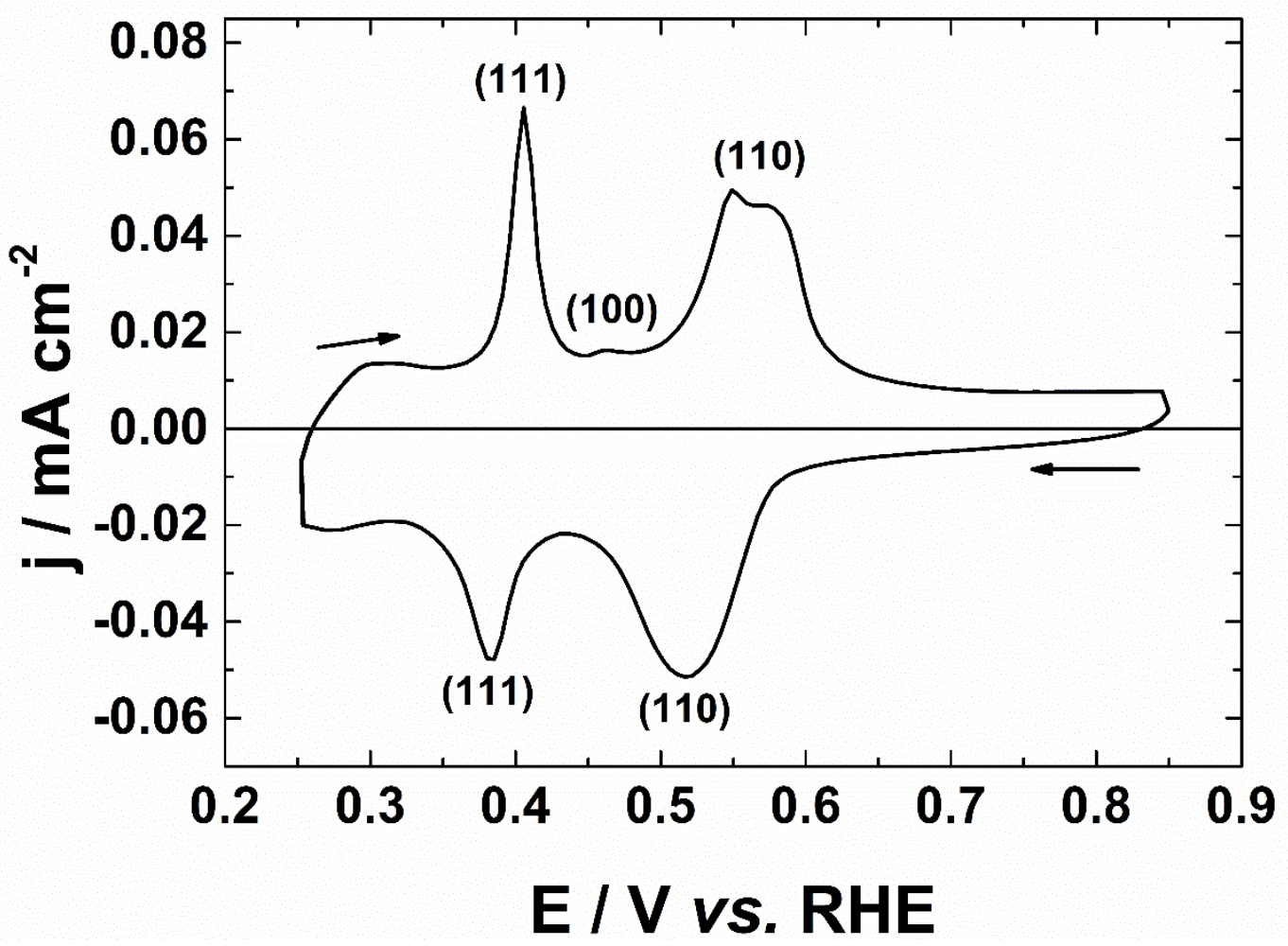

Figure 6: Voltammetric $\mathrm{Pb}_{\text {upd }}$ profile of AuNPs in $0.1 \mathrm{~mol} \mathrm{~L}^{-1} \mathrm{NaOH}+1 \mathrm{mmol} \mathrm{L}^{-1} \mathrm{~Pb}\left(\mathrm{NO}_{3}\right)_{2}$ recorded at $20 \mathrm{mV} \mathrm{s}^{-1}$ at a temperature of $20^{\circ} \mathrm{C}$.

Noble metal surfaces can be characterized by electrochemical methods such as underpotential deposition $(u p d)$ of monolayer of foreign metals [45]. Upd of lead on gold surfaces is a very sensitive electrochemical method to identify and quantify crystallographic orientations, particularly the low index of Miller facets [32, 46-50]. Figure 6 exhibits the CV of AuNPs in 
$0.1 \mathrm{~mol} \mathrm{~L}^{-1} \mathrm{NaOH}$ in the presence of $1 \mathrm{mmol} \mathrm{L}^{-1} \mathrm{~Pb}\left(\mathrm{NO}_{3}\right)_{2}$, at a scan rate of $20 \mathrm{mV} \mathrm{s}^{-1}$. During the negative potential sweep from 0.85 to $0.25 \mathrm{~V} v s$. RHE, a monolayer of lead is deposited at different electrode potentials, on different crystallographic orientations of the surface. During the positive potential sweep, lead desorption occurs reversibly from the electrode surface. The $\mathrm{CV}$ obtained is similar to the CVs shown in the literature for upd of lead on spherical gold nanoparticles $[46,51,52]$. During the deposition step, a wide peak centered at $0.52 \mathrm{~V} v s$. RHE corresponds to (110) facets and defect sites [53]. A second peak that appears at $0.37 \mathrm{~V} v s$. RHE is assigned to (111) facets. Desorption of lead occurs at $0.41 \mathrm{~V} v s$. RHE from (111) facets, at $0.46 \mathrm{~V} v s$. RHE from (100) facets, and at $0.55 \mathrm{~V}$ vs. RHE from (110) facets. The desorption peak associated with (110) facets is split, suggesting the presence of different size domains. It is important to mention that (110) facet is itself a stepped surface represented as 2(111)-(111) in TKL (terrace kink ledge) notation [54]. As the above obtained XRD results demonstrated that AuNPs contain mostly (111) planes, the presence of deposition/desorption peaks from (110) can be attributed to the reconstruction of (111) planes. Moreover, weak dissolution peaks under $0.4 \mathrm{~V}$ vs. RHE assigned to steps or kinks can be distinguished [53].

\subsubsection{Underpotential deposition of lead: effect of a thick oxide growth}

In order to study the contribution of crystallographic orientation at each oxide formation peaks, upd of lead was carried out after growing oxides at different potentials $(1.1 \mathrm{~V}, 1.2 \mathrm{~V}, 1.3 \mathrm{~V}$, $1.4 \mathrm{~V}, 1.5 \mathrm{~V}$ and 1.6 V vs. RHE). Deposition of lead is supposed to not occur on oxide species. The behavior of thick oxide film on gold in alkaline medium is much more complex than in acid medium, which has been largely studied [55-59]. Figure 7 shows the linear polarization recorded prior to oxide growth (polarization at Egrowth during $7200 \mathrm{~s}$ ). The charge associated with the oxide formation during the growth process were calculated by integrating the chronoamperometric curves (no shown here). The values shown in Table 1 clearly indicate that several monolayers of oxides are formed $\left(1 \mathrm{ML}=482 \mu \mathrm{C} \mathrm{cm}^{-2}\right)$. The values of the number of monolayers increase when the value of the upper potential limit increases, especially at $1.6 \mathrm{~V}$ vs. RHE. 


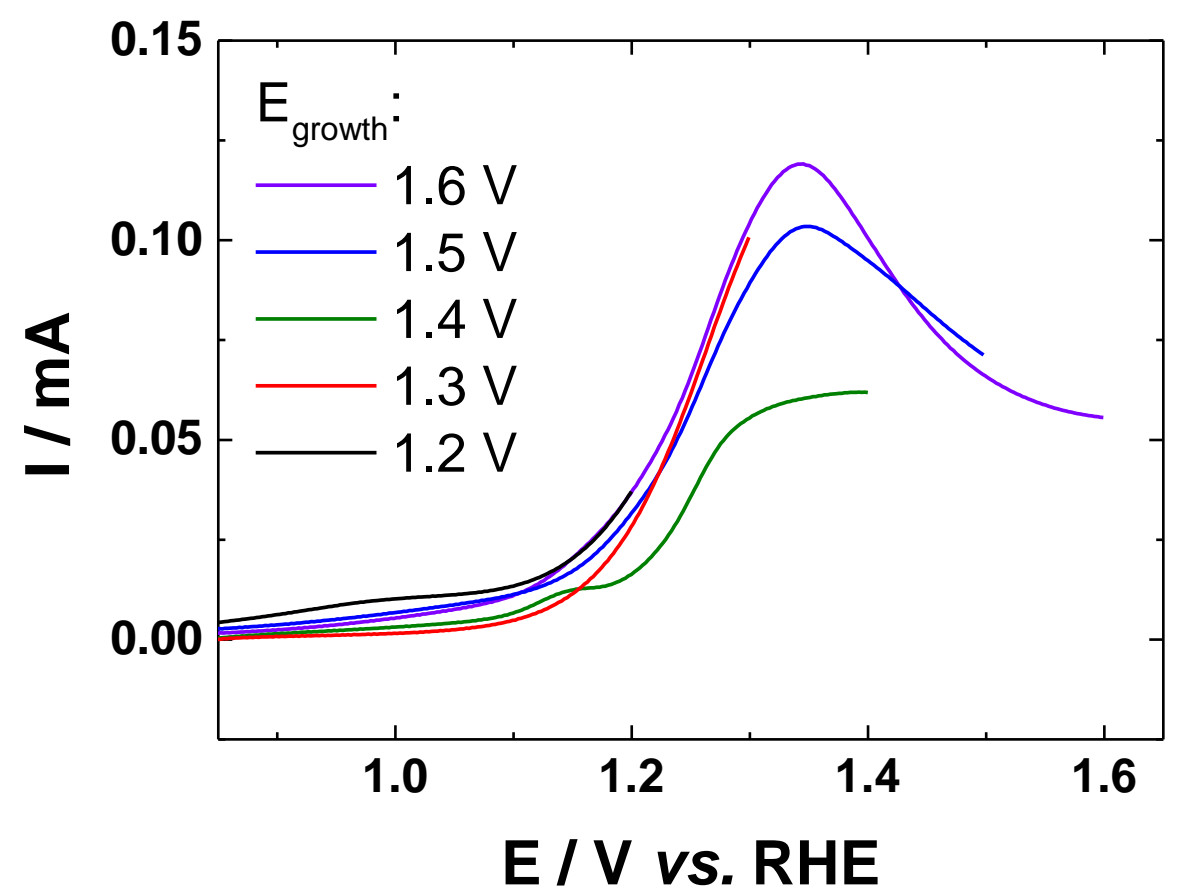

Figure 7: Linear polarization on AuNPs from $0.05 \mathrm{~V} v s$. RHE to Egrowth in $0.1 \mathrm{~mol} \mathrm{~L}^{-1} \mathrm{NaOH}$ recorded at $50 \mathrm{mV} \mathrm{s}^{-1}$ and at a temperature of $20^{\circ} \mathrm{C}$.

Table 1: Values of charges involved during the process of oxide growth (7200 s) and the corresponding number of the formed oxide monolayers.

\begin{tabular}{ccc}
\hline $\mathrm{E}_{\text {growth }} / \mathrm{V} \boldsymbol{\nu s .}$ RHE & Charge $/ \boldsymbol{\mu C \mathbf { ~ c m } ^ { - 2 }}$ & Number of monolayers \\
\hline $\mathbf{1 . 2}$ & 3151 & 6.5 \\
$\mathbf{1 . 3}$ & 3496 & 7.3 \\
$\mathbf{1 . 4}$ & 4130 & 8.6 \\
$\mathbf{1 . 5}$ & 5248 & 10.9 \\
$\mathbf{1 . 6}$ & 18215 & 37.8 \\
\hline
\end{tabular}

Upd of lead was carried out after this oxide growth step, as shown in Figure 8. The oxide region of gold appears as a fingerprint of the crystallographic orientation, like the hydrogen region for platinum [40, 41, 60-62]. In the literature, cyclic voltammograms of single crystals clearly 
demonstrate that the surface structure has a strong influence on this region [40, 41]. However, a given structure does not give a single peak.

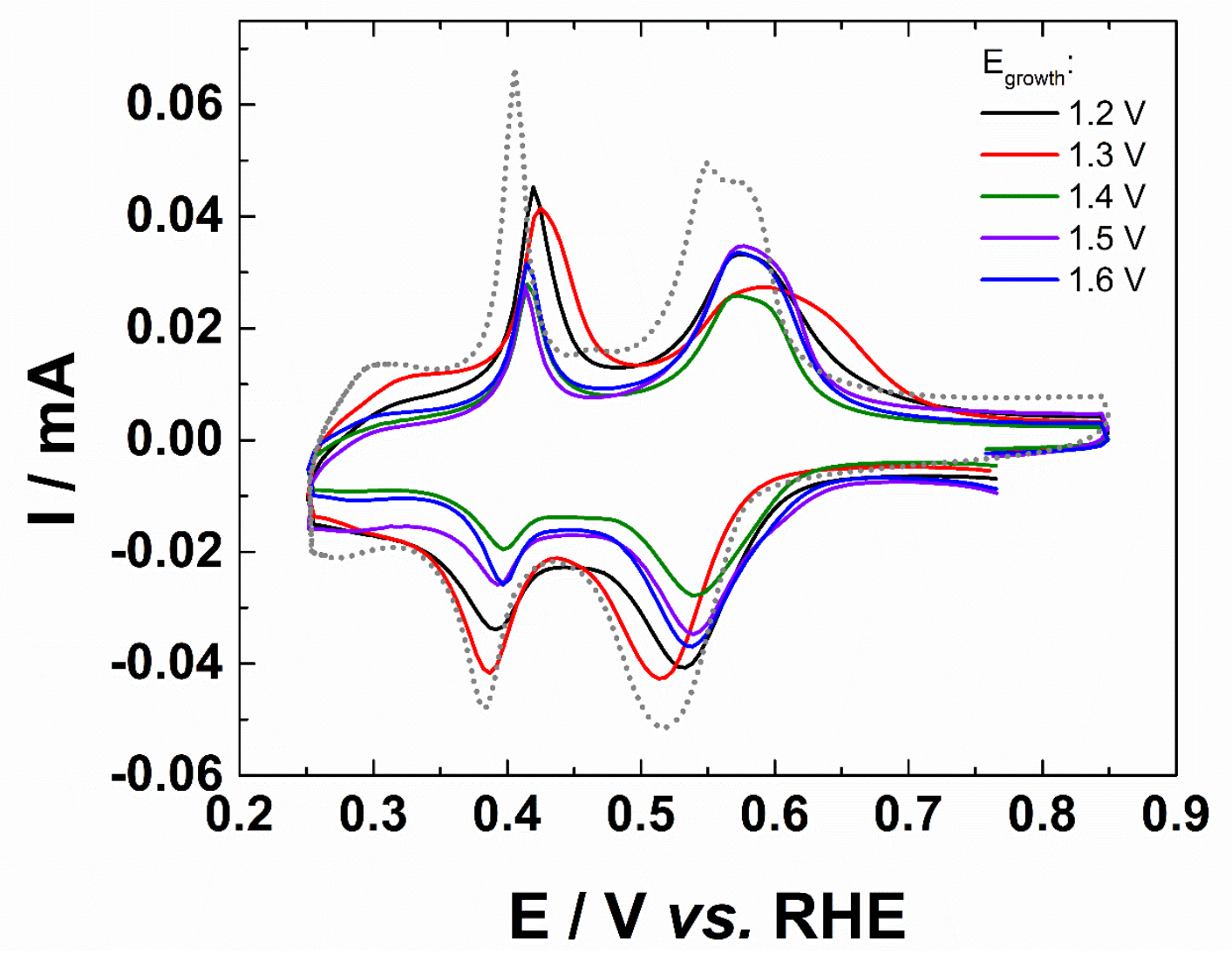

Figure 8: Voltammetric upd profiles of AuNPs in $0.1 \mathrm{~mol} \mathrm{~L}^{-1} \mathrm{NaOH}+1 \mathrm{mmol} \mathrm{L}^{-1} \mathrm{~Pb}\left(\mathrm{NO}_{3}\right)_{2}$ recorded at $20 \mathrm{mV} \mathrm{s}^{-1}$ and at a temperature of $20{ }^{\circ} \mathrm{C}$ after polarization at Egrowth. Dashed line represents upd profile without the oxide growth step.

All the CVs show the same profile that the CV recorded without oxide growth (reproduced as dashed line), with a lower current intensity and shifted peaks. The effect of a thick oxide is not obvious. However, the peak associated with the desorption from the (100) facet, at around 0.45 $\mathrm{V} v s$. RHE, is not observed. This indicates that (100) planes were probably covered by oxides. Moreover, the intensities of the peaks are not the same, indicating the process of oxide growth affected the upd of lead. During the desorption step, the peaks are shifted toward higher potential values, suggesting that the desorption requires more energy than without the growth of oxide layers. For Egrowth of $1.4 \mathrm{~V}$ to $1.6 \mathrm{~V}$ vs. RHE, the deposition peak attributed to (111) facets has a lower intensity than that attributed to (110) facets. The potential of their desorption peak is shifted of $20 \mathrm{mV}$ toward lower potentials in comparison to the peaks of electrodes 
polarized at $1.2 \mathrm{~V}$ and $1.3 \mathrm{~V} v s$. RHE. This shift is certainly caused by a different size of the (111) domains $[46,52,63]$. It can be assumed that the oxidized surface has a different surface energy. This can explain the different observed desorption potentials. The facets (111) are more covered by oxides from $1.4 \mathrm{~V} v s$. RHE, contrary to (110) facets. The process of oxide growth may also consist in a reconstruction of the surface.

\subsection{Carbon monoxide oxidation}

\subsubsection{Effect of the upper limit potential}

Carbon monoxide oxidation was carried out by cyclic voltammetry at different upper potential limits in order to determine the effect of the oxides present at the AuNPs surface. The electrode was first cycled from $0.05 \mathrm{~V} v$ s. RHE to $\mathrm{E}_{\text {sup }}\left(\mathrm{E}_{\text {sup }}=0.8 \mathrm{~V}, 1.0 \mathrm{~V}, 1.2 \mathrm{~V}, 1.4 \mathrm{~V}\right.$ and $1.6 \mathrm{~V} v s$. RHE) (see Figure 5). Then, $\mathrm{CO}$ was introduced in the electrolyte and the open-circuit potential was recorded (Figure 9). Indeed, the open-circuit potential drastically decreased when CO is introduced and the steady-state starts from 300 seconds. This change evidences that $\mathrm{CO}$ has an interaction with the gold surface. In addition, the presence of $\mathrm{CO}$ at the gold electrode surface promotes the adsorption of $\mathrm{HO}^{-}$at low potentials $[1,26]$. Table 2 shows the values of opencircuit potentials recorded before and after 20 minutes of bubbling, according to the upper potential limit applied to cycle in supporting electrolyte. Under inert gas $\left(\mathrm{N}_{2}\right)$, the open-circuit potential is between $0.81 \mathrm{~V}$ and $0.88 \mathrm{~V}$ vs. RHE, while under $\mathrm{CO}$, the open-circuit potential shifts in the range $0.17-0.23 \mathrm{~V}$ vs. RHE. The upper potential limit used during cyclic voltammetry has not a significant influence on the open-circuit potential in the presence of CO. 


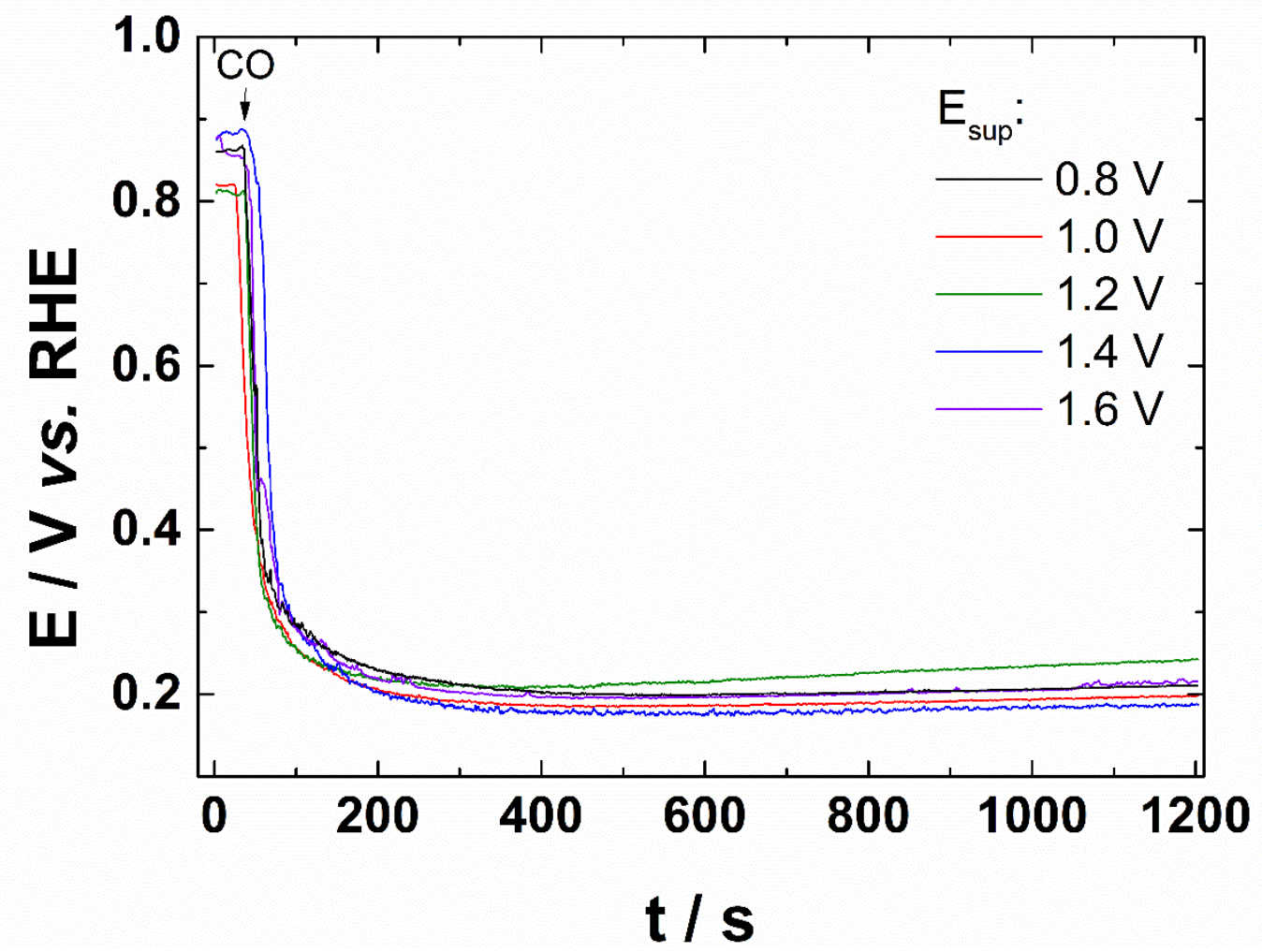

Figure 9: Potentiometric curves in $0.1 \mathrm{~mol} \mathrm{~L}^{-1} \mathrm{NaOH}$ recorded before and after the introduction of $\mathrm{CO}$ in the cell, corresponding to the evolution of the open-circuit potential.

Table 2: Open-circuit potential values obtained in $\mathrm{N}_{2}$ and after the introduction of $\mathrm{CO}$, for different values of upper potential limit.

$\mathrm{E}_{\text {sup }} / \mathrm{V}$ vs. RHE OCP under $\mathrm{N}_{2} / \mathrm{V}$ vs. RHE OCP under CO / V vs. RHE

\begin{tabular}{ccc}
\hline $\mathbf{0 . 8}$ & 0.86 & 0.22 \\
1.0 & 0.82 & 0.21 \\
1.2 & 0.81 & 0.23 \\
1.4 & 0.88 & 0.20 \\
1.6 & 0.86 & 0.17 \\
\hline
\end{tabular}

Figure 10a shows the cyclic voltammogram for CO oxidation obtained on AuNPs at $50 \mathrm{mV} \mathrm{s}^{-1}$, from $0.05 \mathrm{~V}$ to $1.6 \mathrm{~V} v s$. RHE and Figure $10 \mathrm{~b}$ illustrates the positive scan at different rotation 
speeds of the electrode. The diffusion- like shape of these polarization curves showed in Figure $10 \mathrm{~b}$ as function of the rotation rate, underlies a mass-transport limitation of the CO oxidation through the AuNPs electrode surface. The CO oxidation starts around 0.2 V vs. RHE (Fig. 10a. The same value has been observed on gold single crystal electrodes for the oxidation of carbon monoxide in alkaline medium. Compared to the results obtained with spherical AuNPs (from 2 to $60 \mathrm{~nm}$ ) deposited onto ITO electrodes [21], CO oxidation occurs at lower potential at the surface of the present AuNPs. The onset potential of the oxidation of $\mathrm{CO}$ in alkaline medium depends on the crystallographic orientation and the adsorption of hydroxide species [26]. Indeed, calculations revealed the stability of hydroxide species following the order: (110) > $(100)>(111)$, while the onset potential is lower through the reverse order: $(111)>(100)>$ (110) $[10,64]$. These spherical nanoparticles mainly enclose (111) facets, which display lower onset potential than (100) and (110) facets. As pointed out above, a large diffusion plateau is observed from $0.6 \mathrm{~V}$ to $1.3 \mathrm{~V}$ vs. RHE. The current density then decreases from $1.3 \mathrm{~V}$ vs. RHE. During the backward scan, a diffusion plateau starting at $1.25 \mathrm{~V} v s$. RHE is also observed.

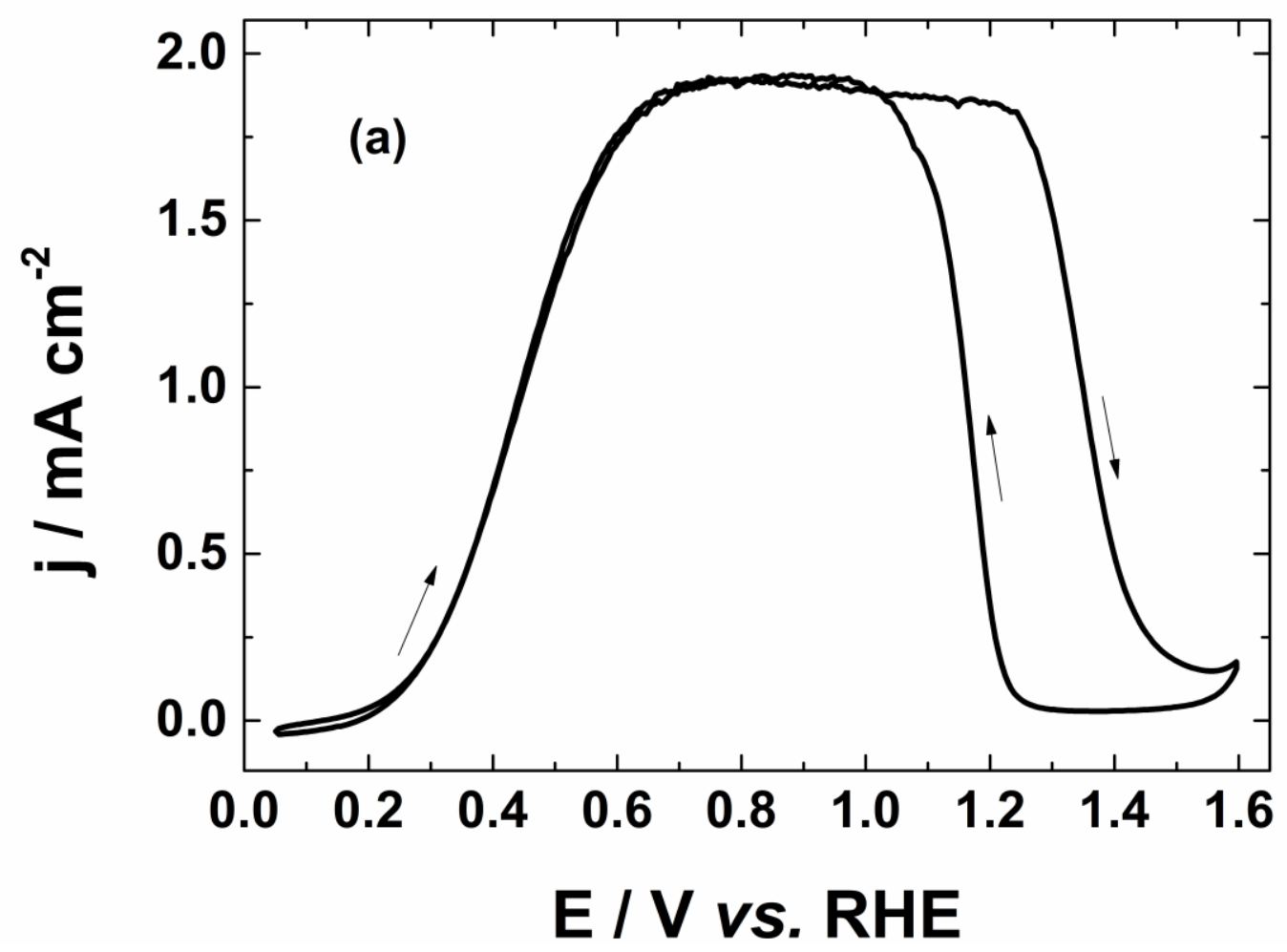




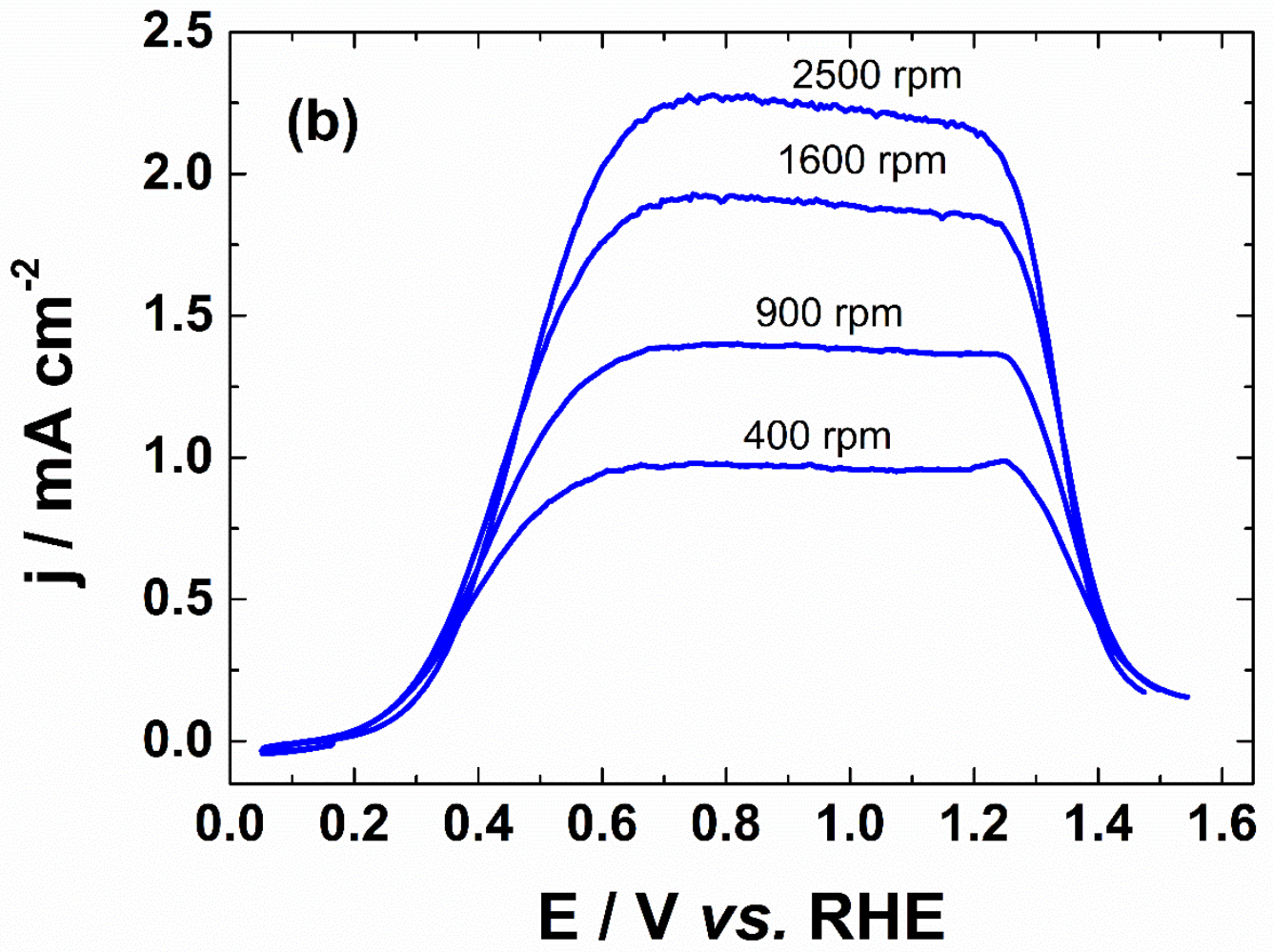

Figure 10: (a) Cyclic voltammogram of AuNPs in CO-saturated $0.1 \mathrm{~mol} \mathrm{~L}^{-1} \mathrm{NaOH}$ recorded at $50 \mathrm{mV} \mathrm{s}^{-1}$, at a temperature of $20^{\circ} \mathrm{C}$ and at $1600 \mathrm{rpm}$; (b) Linear positive scans of AuNPs at different rotation speeds.

Two mechanistic approaches are suggested in the literature for the $\mathrm{CO}$ electrochemical oxidation on gold in alkaline media. The first one from the group of Koper is described as follows $[10,26]$ :

$\mathrm{CO}+*=\mathrm{CO}_{\mathrm{ads}}$

$\mathrm{CO}_{\mathrm{ads}}+\mathrm{HO}^{-}+*=\mathrm{CO}_{\mathrm{ads}}+\mathrm{HO}_{\mathrm{ads}}^{-}$

$\mathrm{CO}_{\mathrm{ads}}+2 \mathrm{HO}_{\mathrm{ads}}^{-}=\mathrm{COOH}_{\mathrm{ads}}+*+\mathrm{e}^{-}+\mathrm{HO}_{\mathrm{ads}}^{-}$(rds)

$\mathrm{COOH}_{\mathrm{ads}}=\mathrm{COO}_{\mathrm{ads}}^{-}+\mathrm{H}^{+}$

$\mathrm{COO}_{\text {ads }}^{-} \rightarrow \mathrm{CO}_{2}+*+\mathrm{e}^{-}$

where $*$ is an active site and $r d s$ the rate determining step. The formed carbon dioxide reacts quickly to form carbonate in alkaline medium. In addition, DFT studies suggest that HO and $\mathrm{CO}$ enhance each other's adsorption when bonded to nearest-neighbor binding sites on gold surface in alkaline medium $[10,26]$. 
The second approach from Roberts et al. [4] considers that interaction between $\mathrm{CO}$ and $\mathrm{OH}^{-}$is very fast, as given:

$\mathrm{CO}+\mathrm{OH}^{-} \rightarrow \mathrm{HOCO}_{\mathrm{ads}}+\mathrm{e}^{-}$

$\mathrm{HOCO}_{\text {ads }}+\mathrm{OH}^{-} \rightarrow \mathrm{OCO}^{-}$ads $+\mathrm{H}_{2} \mathrm{O}$

$\mathrm{OCO}^{-}$ads $+2 \mathrm{OH}^{-} \rightarrow \mathrm{CO}_{3}^{2-}+\mathrm{H}_{2} \mathrm{O}+\mathrm{e}^{-}$

The overall equation from this second approach is the following:

$\mathrm{CO}+4 \mathrm{OH}^{-} \rightarrow \mathrm{CO}_{3}^{2-}+2 \mathrm{H}_{2} \mathrm{O}+2 \mathrm{e}^{-}$

This last mechanism never involves the production of a proton compared to Eq. 4. It suggests several hydroxide species around CO for its oxidation on gold surface.

Figure 11 shows the CVs (first and second cycle) of CO oxidation for different upper potential limits $(0.8 \mathrm{~V}, 1.0 \mathrm{~V}, 1.2 \mathrm{~V}, 1.4 \mathrm{~V}$ and $1.6 \mathrm{~V}$ vs. RHE). Before each experiment under CO, the electrode was cycled from $0.05 \mathrm{~V} v s$. RHE to $\mathrm{E}_{\text {sup. }}$

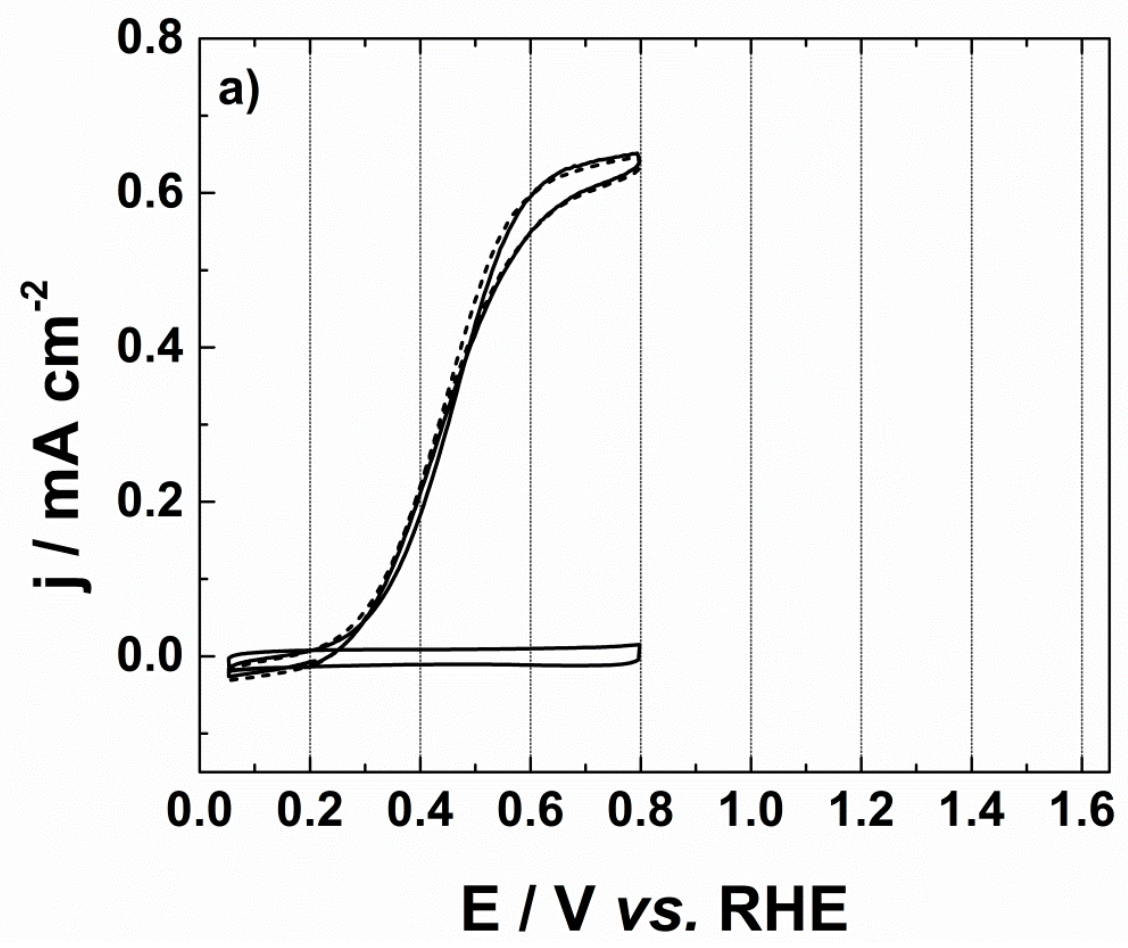



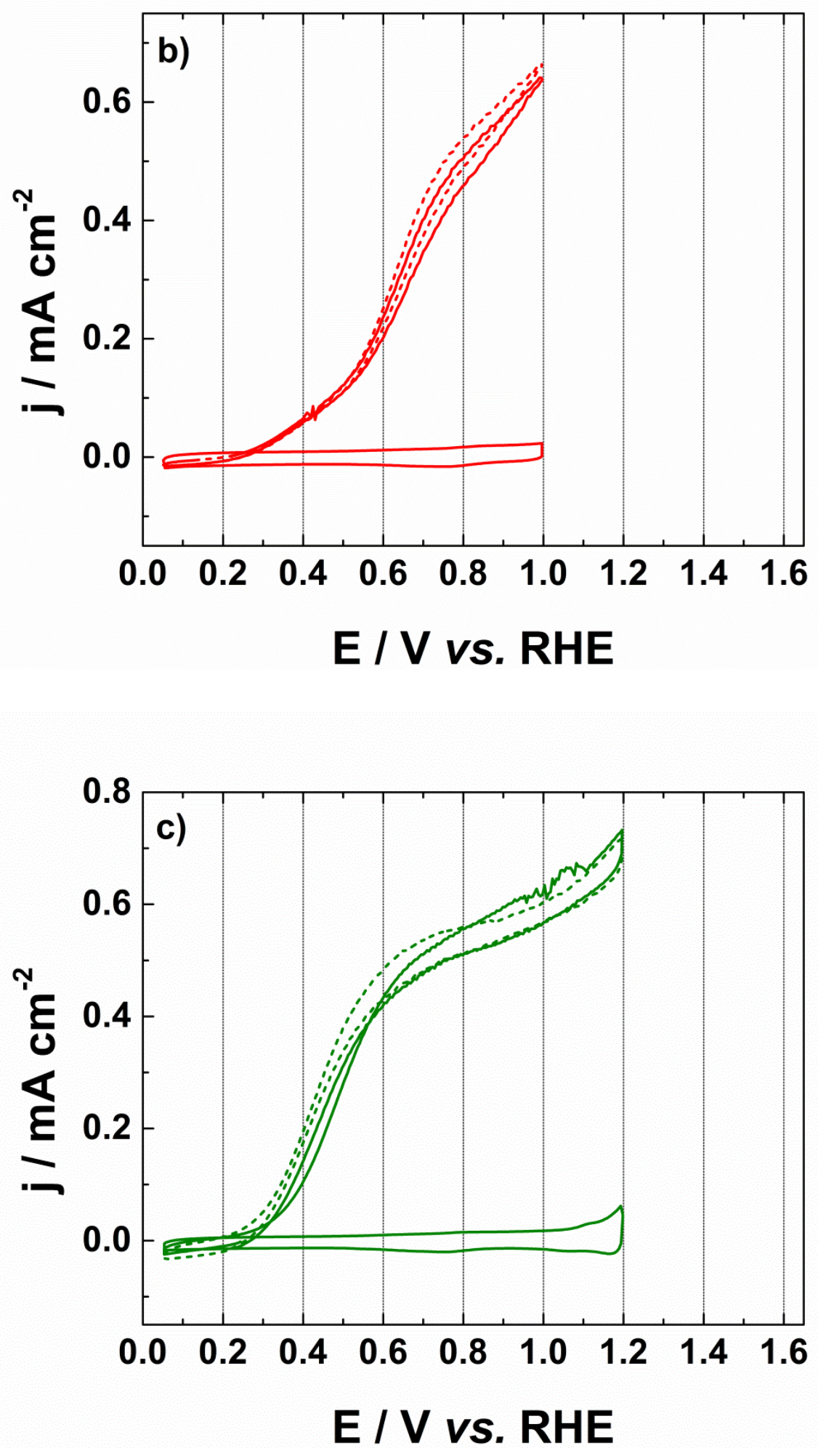

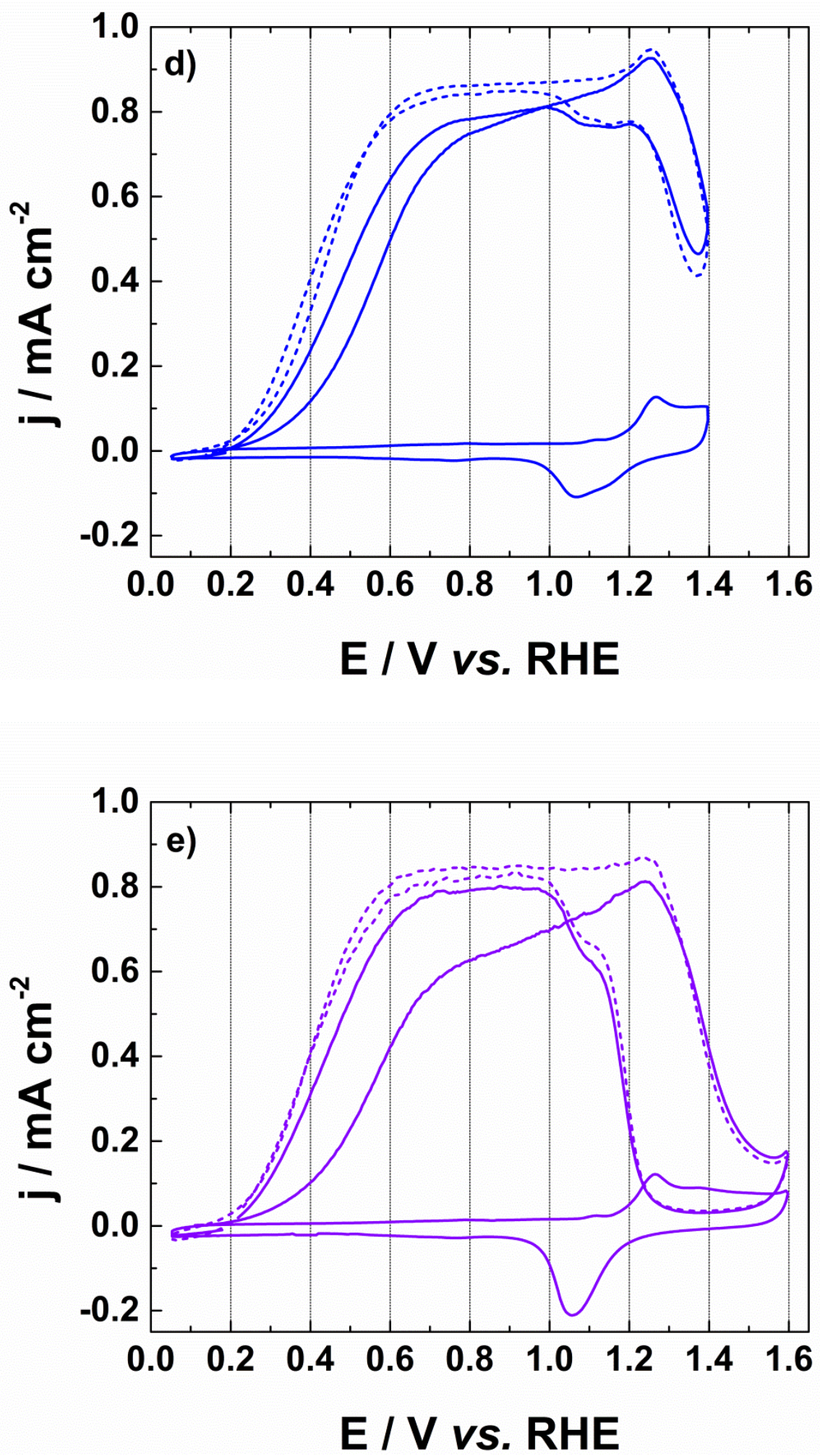

Figure 11: First cyclic voltammograms of AuNPs towards $\mathrm{CO}$ oxidation in $0.1 \mathrm{~mol} \mathrm{~L}^{-1} \mathrm{NaOH}$ recorded at $50 \mathrm{mV} \mathrm{s}^{-1}$ at a temperature of $20{ }^{\circ} \mathrm{C}$ and at $400 \mathrm{rpm}$ according to the upper potential limit $\left(\mathrm{E}_{\text {sup }}\right):$ a) $0.8 \mathrm{~V}$, b) $1.0 \mathrm{~V}$, c) $1.2 \mathrm{~V}$, d) $1.4 \mathrm{~V}$, e) $1.6 \mathrm{~V} v s$. RHE. Solid line is corresponding 
to the first cycle and the dashed one, to the second cycle. The cyclic voltammogram of AuNPs in $\mathrm{N}_{2}$ from $0.05 \mathrm{~V} v s$. RHE to $\mathrm{E}_{\text {sup }}$ is displayed.

Below the potentials of gold surface oxidation (below $1.0 \mathrm{~V} v s$. RHE), CO is weakly adsorbed with a fractional coverage $\theta_{\mathrm{CO}}<0.1$ [14]. It is known that the adsorption of hydroxide species occurs between $0.3 \mathrm{~V}$ and $1.1 \mathrm{~V} v s$. RHE [42]. When the upper potential limit is $0.8 \mathrm{~V} v$. RHE (Figure 11a), the first cycle is the same than the second one, indicating no change in the surface structure. Furthermore, the first cycle at $\mathrm{E}_{\text {sup }}=0.8 \mathrm{~V} v s$. RHE displays a lower onset potential than the other voltammograms. $\mathrm{CO}$ oxidation occurs even at low $\mathrm{CO}$ coverage. When $\mathrm{E}_{\text {sup }}=1.0 \mathrm{~V} v s$. RHE (Figure 11b), the second cycle of CO oxidation is shifted toward lower potential, indicating the beginning of the surface reconstruction. At higher upper potential limits, when the oxides layer starts to be formed, the changes between the first and second cycles are more obvious. Indeed, more molecules of $\mathrm{CO}$ are adsorbed at potentials higher than $1.0 \mathrm{~V} v s$. RHE and the amount of hydroxide species decreases. For $\mathrm{E}_{\text {sup }} \geq 1.4 \mathrm{~V} v s$. RHE (Figures 11d and 11e), the second cycle shifts more than $100 \mathrm{mV}$ toward lower potential and displays a higher current density. More active sites are available for the reaction after the first cycle, which probably enhances the formation of hydroxide species. The current decreases after the diffusion plateau as the formation of oxides occurs. The diffusion plateau occurring at the backward scan has an onset potential coinciding with the reduction of oxides species. This phenomenon indicates the major and crucial role of hydroxide species in the $\mathrm{CO}$ oxidation reaction. In addition, the process of oxidation/reduction of gold surface improves the reaction by creating more active sites.

\section{Conclusion}

Unsupported spherical AuNPs were successfully synthesized by a revisited Turkevich method. Particularly, the role of the oxides was investigated. Characterizations such as TEM and XRD shows that AuNPs are quasi-spherical with diameters of $23.04 \pm 3.37 \mathrm{~nm}$ and with the predominance of (111) facets. Electrochemical characterizations undertaken with cyclic voltammetry and upd of lead, were employed to reveal the surface state of these AuNPs. For this purpose, electrochemical CO oxidation was investigated in alkaline medium. The role of hydroxide species towards $\mathrm{CO}$ oxidation was highlighted. $\mathrm{CO}$ oxidation does not occur when the surface is oxidized. However, the reconstruction of the surface and the process of formation/reduction of the gold oxides enhance the $\mathrm{CO}$ oxidation in terms of current density and onset potential. Moreover, the onset potential of $0.2 \mathrm{~V} v$ s. RHE observed for the CO 
oxidation with the synthesized AuNPs is close to the values reported for gold single crystals. This value is much lower than those reported for gold nanoparticles.

\section{Acknowledgements}

The authors acknowledge financial support from the European Union (ERDF) and "Région Nouvelle Aquitaine". 


\section{References}

1. P. Rodriguez, Y. Kwon, M. T. M. Koper, Nat. Chem. 4, 177-182 (2012)

2. W. Napporn, J.-M. Léger, C. Lamy, J. Electroanal. Chem. 408, 141-147 (1996)

3. B. Hammer, J. K. Norskov, Nature 376, 238-240 (1995)

4. J. L. Roberts, D. T. Sawyer, Electrochim. Acta 10, 989-1000 (1965)

5. M. Haruta, S. Tsubota, T. Kobayashi, H. Kageyama, M. J. Genet, B. Delmon, J. Catal. 144, 175-192 (1993)

6. M. Haruta, T. Kobayashi, H. Sano, N. Yamada, Chem. Lett. 16, 405-408 (1987)

7. G. J. Edens, A. Hamelin, M. J. Weaver, J. Phys. Chem. 100, 2322-2329 (1996)

8. B. B. Blizanac, M. Arenz, P. N. Ross, N. M. Markovic, J Am Chem Soc 126, 10130-10141 (2004)

9. G. L. Beltramo, T. E. Shubina, M. T. Koper, ChemPhysChem 6, 2597-2606 (2005)

10. P. Rodriguez, N. Garcia-Araez, M. T. M. Koper, Phys. Chem. Chem. Phys. 12, 9373-9380 (2010)

11. N. Lopez, T. V. W. Janssens, B. S. Clausen, Y. Xu, M. Mavrikakis, T. Bligaard, J. K. Norskov, J. Catal. 223, 232-235 (2004)

12. C. Xu, J. Su, X. Xu, P. Liu, H. Zhao, F. Tian, Y. Ding, J Am Chem Soc 129, $42-43$ (2007)

13. L. W. Guo, P. P. Du, X. P. Fu, C. Ma, J. Zeng, R. Si, Y. Y. Huang, C. J. Jia, Y. W. Zhang,

C. H. Yan, Nat. Commun. 7, 13481-13488 (2016)

14. S. C. Chang, A. Hamelin, M. J. Weaver, J. Phys. Chem. 95, 5560-5567 (1991)

15. P. Rodriguez, J. M. Feliu, M. T. Koper, Electrochem. Commun. 11, 1105-1108 (2009)

16. P. Rodriguez, D. Plana, D. J. Fermin, M. T. M. Koper, J. Catal. 311, 182-189 (2014)

17. S. Lai, N. Lebedeva, T. Housmans, M. Koper, Top. Catal. 46, 320-333 (2007)

18. S. C. Chang, A. Hamelin, M. J. Weaver, J. Phys. Chem. 95, 5560-5567 (1991)

19. I. N. Remediakis, N. Lopez, J. K. Norskov, Appl. Catal. A: Gen 291, 13-20 (2005)

20. S. D. Senanayake, D. Stacchiola, P. Liu, C. B. Mullins, J. Hrbek, J. A. Rodriguez, J. Phys. Chem. C 113, 19536-19544 (2009)

21. S. Kumar, S. Zou, J. Phys. Chem. B 109, 15707-15713 (2005)

22. D. Geng, G. Lu, J. Nanopart. Res. 9, 1145-1151 (2007)

23. M. M. Maye, Y. Lou, C.-J. Zhong, Langmuir 16, 7520-7523 (2000)

24. A. Piednoir, M. Languille, L. Piccolo, A. Valcarcel, F. C. S. Aires, J. Bertolini, Catal. Lett. 114, 110-114 (2007) 
25. J.-H. Liu, A.-Q. Wang, Y.-S. Chi, H.-P. Lin, C.-Y. Mou, J. Phys. Chem. B 109, 40-43 (2005)

26. P. Rodríguez, A. A. Koverga, M. T. Koper, Angew. Chem. Int. Ed. 49, 1241-1243 (2010)

27. J. Turkevich, P. C. Stevenson, J. Hillier, Discuss. Faraday Soc. 11, 55-75 (1951)

28. H. Tyagi, A. Kushwaha, A. Kumar, M. Aslam, Nanoscale Res. Lett. 362-373 (2016)

29. J. Kimling, M. Maier, B. Okenve, V. Kotaidis, H. Ballot, A. Plech, J. Phys. Chem. B 110, 15700-15707 (2006)

30. M. O. Finot, G. D. Braybrook, M. T. McDermott, J. Electroanal. Chem. 466, 234-241 (1999)

31. U. Oesch, J. Janata, Electrochim. Acta 28, 1237-1246 (1983)

32. S. Hebie, L. Cornu, T. W. Napporn, J. Rousseau, B. K. Kokoh, J. Phys Chem. C 117, $9872-$ 9880 (2013)

33. A. J. Trouiller, S. Hebie, F. El Bahhaj, T. W. Napporn, P. Bertrand, Eur J Med Chem 99, 92-112 (2015)

34. W. Haiss, N. T. K. Thanh, J. Aveyard, D. G. Fernig, Anal. Chem. 79, 4215-4221 (2007)

35. H. Erikson, A. Sarapuu, J. Solla-Gullón, K. Tammeveski, J. Electroanal. Chem. 780, 327$336(2016)$

36. S. Hebie, Y. Holade, K. Maximova, M. Sentis, P. Delaporte, K. B. Kokoh, T. W. Napporn,

A. V. Kabashin, ACS Catal. 5, 6489-6496 (2015)

37. S. Link, M. A. El-Sayed, J Phys Chem B 103, 8410-8426 (1999)

38. C. C. Li, K. L. Shuford, Q. H. Park, W. P. Cai, Y. Li, E. J. Lee, S. O. Cho, Angew. Chem.Int. Edit. 46, 3264-3268 (2007)

39. Y. Chen, A. A. Fernandes, A. Erbe, Electrochim. Acta 113, 810-816 (2013)

40. A. Hamelin, A. M. Martins, J. Electroanal. Chem. 407, 13-21 (1996)

41. A. Hamelin, J. Electroanal. Chem. 407, 1-11 (1996)

42. M. W. Hsiao, R. R. Adzic, E. B. Yeager, J Electrochem Soc 143, 759-767 (1996)

43. C. Alegre, A. Stassi, E. Modica, C. Lo Vecchio, A. Aricò, V. Baglio, RSC Adv. 5, 2542425427 (2015)

44. S. Štrbac, R. R. Adzic, J. Electroanal. Chem. 403, 169-181 (1996)

45. E. Herrero, L. J. Buller, H. D. Abruna, Chem. Rev. 101, 1897-1930 (2001)

46. J. Hernandez, J. Solla-Gullon, E. Herrero, J. M. Feliu, A. Aldaz, J. Nanosci. Nanotechnol. 9, 2256-2273 (2009)

47. A. Hamelin, J. Electroanal. Chem. 101, 285-290 (1979)

48. A. Hamelin, A. Katayama, G. Picq, P. Vennereau, J. Electroanal. Chem. 113, 293-300 (1980) 
49. A. Hamelin, J. Lipkowski, J. Electroanal. Chem. 171, 317-330 (1984)

50. A. Hamelin, J. Electroanal. Chem. 165, 167-180 (1984)

51. C. Jeyabharathi, M. Zander, F. Scholz, J Electroanal Chem 819, 159-162 (2017)

52. J. Hernandez, J. Solla-Gullon, E. Herrero, J Electroanal Chem 574, 185-196 (2004)

53. S. Pedireddy, H. K. Lee, C. S. L. Koh, J. M. R. Tan, W. W. Tjiu, X. Y. Ling, Small 12, 4531-4540 (2016)

54. B. Lang, R. W. Joyner, G. A. Somorjai, Surf. Sci 30, 454-474 (1972)

55. G. Tremiliosi-Filho, L. H. Dall'Antonia, G. Jerkiewicz, J. Electroanal. Chem. 578, 1-8 (2005)

56. G. Tremiliosi-Filho, L. H. DallAntonia, G. Jerkiewicz, J. Electroanal. Chem. 422, 149-159 (1997)

57. B. E. Conway, B. Barnett, H. Angerstein-Kozlowska, B. V. Tilak, J Chem Phys 93, 83618373 (1990)

58. L. D. Burke, M. McRANN, J. Electroanal. Chem. Interfacial Electrochem. 125, 387-399 (1981)

59. L. Burke, P. Nugent, Gold Bull 30, 43-53 (1997)

60. S. Štrbac, A. Hamelin, R. R. Adzić, J. Electroanal. Chem. 362, 47-53 (1993)

61. J. Solla-Gullón, F. Vidal-Iglesias, P. Rodriguez, E. Herrero, J. Feliu, J. Clavilier, A. Aldaz, J. Phys. Chem. B 108, 13573-13575 (2004)

62. J. Solla-Gullón, F. Vidal-Iglesias, E. Herrero, J. Feliu, A. Aldaz, Electrochem Commun 8, 189-194 (2006)

63. J. Hernandez, J. Solla-Gullon, E. Herrero, A. Aldaz, J. M. Feliu, J. Phys. Chem. B 109, 12651-12654 (2005)

64. A. M. Pessoa, J. L. C. Fajín, J. R. B. Gomes, M. N. D. S. Cordeiro, Theochem-J. Mol. Struct. 946, 43-50 (2010) 


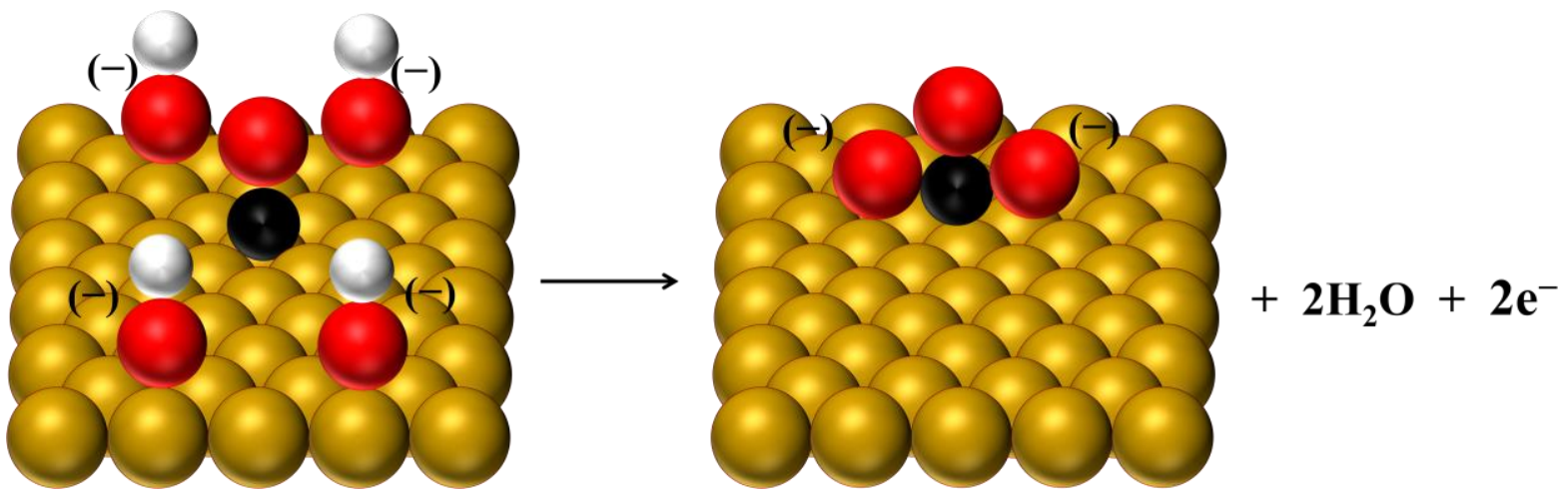

